\title{
Evaluation of an in vivo model for ventricular shunt infection: a pilot study using a novel antimicrobial-loaded polymer
}

\author{
Rajiv R. Iyer, MD, ${ }^{1}$ Noah Gorelick, MD, ${ }^{1}$ Karen Carroll, MD, ${ }^{3}$ Ari M. Blitz, MD, ${ }^{2}$ \\ Sarah Beck, DVM, PhD, ${ }^{4}$ Caroline M. Garrett, DVM, ${ }^{4}$ Audrey Monroe, ${ }^{1}$ Betty Tyler, BA, ${ }^{1}$ \\ Sean T. Zuckerman, PhD, ${ }^{5}$ Jeffrey R. Capadona, PhD, ${ }^{5,6}$ Horst A. von Recum, PhD, ${ }^{5}$ and \\ Mark G. Luciano, MD, PhD ${ }^{1}$
}

\begin{abstract}
Departments of ${ }^{1}$ Neurosurgery, ${ }^{2}$ Radiology, ${ }^{3}$ nfectious Diseases, and ${ }^{4}$ Molecular and Comparative Pathobiology, Johns Hopkins University School of Medicine, Baltimore, Maryland; ${ }^{5}$ Department of Biomedical Engineering, Case Western Reserve University, Cleveland; and ${ }^{6}$ Advanced Platform Technology Center, Rehabilitation Research and Development, Louis Stokes Cleveland VA Medical Center, Cleveland, Ohio
\end{abstract}

OBJECTIVE Ventricular shunt infection remains an issue leading to high patient morbidity and cost, warranting further investigation. The authors sought to create an animal model of shunt infection that could be used to evaluate possible catheter modifications and innovations.

METHODS Three dogs underwent bilateral ventricular catheter implantation and inoculation with methicillin-sensitive Staphylococcus aureus (S. aureus). In 2 experimental animals, the catheters were modified with a polymer containing chemical "pockets" loaded with vancomycin. In 1 control animal, the catheters were polymer coated but without antibiotics. Animals were monitored for 9 to 11 days, after which the shunts were explanted. MRI was performed after shunt implantation and prior to catheter harvest. The catheters were sonicated prior to microbiological culture and also evaluated by electron microscopy. The animals' brains were evaluated for histopathology.

RESULTS All animals underwent successful catheter implantation. The animals developed superficial wound infections, but no neurological deficits. Imaging demonstrated ventriculitis and cerebral edema. Harvested catheters from the control animal demonstrated $>10^{4}$ colony-forming units (CFUs) of S. aureus. In the first experimental animal, one shunt demonstrated $>10^{4} \mathrm{CFU}$ s of $S$. aureus, but the other demonstrated no growth. In the second experimental animal, one catheter demonstrated no growth, and the other grew trace $S$. aureus. Brain histopathology revealed acute inflammation and ventriculitis in all animals, which was more severe in the control.

CONCLUSIONS The authors evaluated an animal model of ventricular shunting and reliably induced features of shunt infection that could be microbiologically quantified. With this model, investigation of pathophysiological and imaging correlates of infection and potentially beneficial shunt catheter modifications is possible.

https://thejns.org/doi/abs/10.3171/2018.1.JNS172523

KEYWORDS antibiotics; catheter; coating; infection; polymer; cyclodextrin; shunt; Staphylococcus aureus; vancomycin; ventriculitis; hydrocephalus

$\mathrm{V}$ ENTRICULAR shunt infection remains a frustrating, costly, and morbid problem following cerebrospinal fluid (CSF) shunting procedures, despite advances in operative technique and surgical safety. ${ }^{1,14}$ When these infections occur, the entire shunt system is typically explanted and temporarily replaced by an external ventricular drain, followed by an extended course of in-hospital antibiotics and subsequent shunt replacement. Although the rate of shunt infection varies between institutions, this phenomenon is not uncommon, and recent studies

ABBREVIATIONS AIC = antibiotic-impregnated catheter; CFU = colony-forming unit.

SUBMITTED October 6, 2017. ACCEPTED January 15, 2018.

INCLUDE WHEN CITING Published online August 3, 2018; DOI: 10.3171/2018.1.JNS172523. 
have highlighted potential risk factors for its occurrence, including patient age, ethnicity, insurance status, recent prior shunt revisions, etiology of hydrocephalus, surgeon experience, and intraoperative factors, such as catheter handling or hardware contamination. . $^{6,18,32,42,43,47}$

Because the adverse clinical and economic consequences of shunt infection are significant, efforts have been made over the years to reduce the incidence by focusing on realistically modifiable risk factors. For example, peri- or intraoperative antibiotics, double gloving, and multiinstitutional standardized surgical protocols have all been implemented, with varying levels of efficacy in decreasing shunt infection rates. $13,26,27,36,37,46$

The majority of shunt infections are caused by grampositive organisms thought to adhere to the silicone ventricular catheter at the time of initial surgery. ${ }^{10}$ In light of this, attempts in recent decades to reduce shunt infection rates have also included evaluation of the role of antibiotic-impregnated catheters (AICs) to prevent bacterial colonization of the shunt catheter., ${ }^{7,911,20,29}$ Utilization of AICs has demonstrated overall improvement in clinical and economic outcomes secondary to a lower incidence of shunt infection, although some heterogeneity has been reported regarding their positive effects. , $, 5,22,24,25,28,30,34,40^{2}$

Despite these efforts, shunt infection remains a problem that warrants additional investigation, given its ongoing occurrence and morbidity. While continued clinical studies are required, experimental and preclinical studies allow for evaluation of questions that are not easily addressed in the clinical setting. The pathophysiology of specific infections, their spread through tissues, and pathological imaging correlates can be studied, along with feasibility and risks of new materials and devices. To adequately explore opportunities for improvement and innovation in this area, in vivo models for shunt infection have been described. 8,20 However, existing models are limited due to several features, including lack of variability of bacterial species and virulence, lack of ability to quantify bacterial type and presence, and lack of ability to provide imaging correlates of infection. In this study, we sought to generate an improved, robust animal model of shunt infection, and we used this model to test a modified ventricular catheter that could serve as a potential avenue of therapeutic benefit.

\section{Methods}

\section{Animals}

Intact adult male purpose-bred mongrel dogs (Canis lupus familiaris; $\mathrm{n}=3$; age 8 to 10 months; $27.5 \pm 2.5$ $\mathrm{kg}$ ) from Marshall Farms were used in this study. The animals were singly housed in $4 \times 6$-foot runs in rooms maintained at $70^{\circ} \mathrm{F} \pm 2^{\circ} \mathrm{F}$ with $30 \%$ to $70 \%$ relative humidity and kept under a 12:12-hour light/dark cycle. They were provided commercial dog chow (Teklad diet 2025, Harlan-Teklad), unrestricted access to reverse osmosis water and daily enrichment (Nylabone Durachews), and exercise by the care staff. All dogs were deemed healthy based on a preoperative physical examination and hematological and biochemical analyses. All procedures performed were under an approved Animal Care and Use Committee protocol in accordance with the Guide for the Care and Use of Laboratory Animals, ${ }^{17}$ Public Health Service Policy on Humane Care and Use of Laboratory Animals, ${ }^{33}$ and Animal Welfare Act and Regulations. ${ }^{2}$

\section{Perioperative Animal Preparation, Anesthesia, and Analgesia}

The planned experimental protocol involved 2 separate surgeries: first, implantation of bilateral ventricular shunt catheters and bacterial inoculation, and after approximately 10 days, a second surgery involving catheter and associated biological sample harvest and animal perfusion. In the interval between surgeries, animals were kept in the care facility and monitored for clinical behavior, vital signs, and food and water intake. Food was withheld for 12 hours prior to both surgeries. All dogs were premedicated with $0.03 \mathrm{mg} / \mathrm{kg}$ acepromazine (VetOne) and $5 \mu \mathrm{g} / \mathrm{kg}$ dexmedetomidine (Dexdomitor, Pfizer Animal Health) administered via an intramuscular route. They were induced with $5 \mathrm{mg} / \mathrm{kg}$ propofol (Propoflo 28, Abbott Animal Health) intravenously until endotracheal intubation could be performed safely. All dogs were maintained under a surgical plane of anesthesia with isoflurane (Fluriso, VetOne) in oxygen for the duration of the surgical procedure. Intravenous isotonic saline (Hospira) was administered at a flow rate of $5 \mathrm{ml} / \mathrm{kg} / \mathrm{hr}$. Postoperative analgesia consisted of $0.6 \mathrm{mg} / \mathrm{kg}$ sustained-release meloxicam (MeloxicamSR, ZooPharm) and $0.2 \mathrm{mg} / \mathrm{kg}$ sustained-release buprenorphine (BupSR, ZooPharm) administered subcutaneously.

\section{Proximal Ventricular Catheter Modification}

Standard silastic proximal shunt catheters were modified by applying a polysaccharide-based polymer coating on both the inner luminal and outer surfaces. This polymer is made by cross-linking cyclodextrin in the presence of an implant, resulting in a surface coating featuring a high water content and hydrophilicity, and also creating an ultrastructural architecture featuring molecular "pockets" capable of drug loading and delivery. ${ }^{21,45}$ To do this, silastic shunts were swelled, which promoted polymer chain entanglement and adhesion on the catheter surfaces on application, and exposed to oxygen plasma to generate surface radicals. The shunts were plasma treated for 2 minutes, and immediately coated with $25 \mathrm{wt} \%$ cyclodextrin (CD) prepolymer mixed with ethylene glycol diglycidyl ether (EGDGE) at a molar ratio of 1:0.7 CD/ EGDGE in $N, N$-dimethylformamide, and polymerized for 30 minutes at $60^{\circ} \mathrm{C}$. The coated shunts were removed and washed extensively in distilled water for 3 days, replacing the water periodically to wash out solvent and excess reagents. After washing, each shunt was partially dried, and vancomycin was loaded by incubating shunts in a $5 \%(\mathrm{wt} / \mathrm{vol})$ aqueous vancomycin solution for 2 days. After 2 days the catheters were briefly rinsed to remove excess, unbound drug. All catheters were coated with the polymer. Only the experimental catheters were loaded with vancomycin, while the control catheters were kept antibiotic free. Catheter sterilization was performed using ethylene oxide gas, previously demonstrated to not impact drug stability and release..$^{19}$ 


\section{Proximal Catheter Insertion and Inoculation}

On the day of initial surgery, the animals were placed prone, and their heads were shaved and prepped in a sterile fashion. Perioperative antibiotics were withheld to ensure the ability to induce infection. A midline skin incision was made about $3 \mathrm{~cm}$ posterior to the glabella, and the temporalis muscle was reflected from the skull in a subperiosteal fashion, exposing a substantial portion of the anterior cranium. Burr holes were made in the bilateral frontal regions posterior to the frontal sinuses and anterior to the coronal sutures, approximately $2 \mathrm{~cm}$ lateral to midline. The dura was opened, and hemostasis was achieved. Bilateral frontal-approach ventriculostomy catheters were then cut to $2.5 \mathrm{~cm}$ and passed toward the lateral ventricles using a stylet. In 2 experimental animals, paired bilateral proximal catheters were coated with polymer and impregnated with vancomycin. In 1 control animal, implanted bilateral proximal catheters had polymer coating alone without an antibiotic. Surgeons and the experimental team were blinded to the antibiotic status of the catheters (antibiotic vs no antibiotic). Following catheter insertion, approximately $40 \mu \mathrm{l}$ of $0.85 \%$ saline containing $1 \times 10^{8}$ colony-forming units (CFUs) of Staphylococcus aureus (S. aureus) was inoculated into each ventricular catheter using a tuberculin syringe. Bone wax was used to seal the inoculum within the catheters and to seal the burr holes. The skin was closed in a layered fashion.

\section{Animal Imaging}

Immediately following ventricular insertion surgery, animals were transferred under general anesthesia to the animal imaging facility for magnetic resonance imaging (MRI). Imaging was performed on a 3.0-T scanner (MAGNETOM). Imaging included T1-weighted pre- and postcontrast, T2-weighted, FLAIR, constructive interference in steady state (CISS), and diffusion-weighted imaging (DWI) sequences. After imaging, the animals were taken to the recovery room for extubation and recovery. Between 7 (control animal) and 10 days (experimental animals) following initial surgeries, each animal underwent a second MRI study with identical scan sequences.

\section{Catheter Removal and Sampling}

Between 9 and 11 days after the initial surgery, the animals were taken back to the operating room for ventricular catheter removal and sampling. Under general anesthesia, each animal underwent a high cervical cisternal tap to sample CSF. Blood cultures were incubated in the BACTEC FX (BD) continuous monitoring blood culture instrument for 5 days, and positives were processed as per standard operating procedures. The scalp wounds were reopened, and the catheters were identified bilaterally within each burr hole. Upon removal of the catheters, a small piece of the tip was cut off and processed for electron microscopy. The remainder of each catheter was stored sterilely for microbiological evaluation. Following catheter removal, a microforceps was used to sample superficial and deep brain parenchyma adjacent to the catheter tracks. The animals were then deeply anesthetized for transcardial perfusion using phosphate-buffered saline (PBS), and the brains were harvested and stored using $10 \%$ neutralbuffered formalin (NBF).

\section{Microbiology}

Blood cultures were processed as described above. Tissue samples and CSF samples were inoculated to 5\% sheep blood and chocolate agars and were incubated using routine microbiological protocols. Ventricular catheters were processed using a sonication procedure to evaluate for bacterial adherence to the silicone tubing. The catheter tips were placed in a vial containing $5 \mathrm{ml}$ of saline and sonicated for 1 minute at $40 \mathrm{kHz} ; 0.1 \mathrm{ml}$ was then directly spread onto a 5\% sheep blood agar plate. Two rounds of serial dilutions were then performed in a similar fashion. Plates were incubated at $35^{\circ} \mathrm{C}$ for $24-48$ hours, and colony numbers were counted on each plate. Organisms were identified using latex agglutination for staphylococci and matrix-assisted laser desorption ionization time-of-flight mass spectrometry for definitive species identification.

\section{Electron Microscopy}

Following explantation, shunt catheter tips were fixed in $2.5 \%$ glutaraldehyde and $3 \mathrm{mM}$ magnesium chloride in 0.1 $\mathrm{M}$ sodium cacodylate buffer at a $\mathrm{pH}$ of 7.2 overnight at $4^{\circ} \mathrm{C}$. After buffer rinse, samples were postfixed in $1 \%$ osmium tetroxide in $0.1 \mathrm{M}$ sodium cacodylate buffer for 1 hour on ice in the dark. Following a distilled water rinse, the samples were dehydrated in a graded series of ethanol and left to dry overnight with hexamethyldisilazane (HDMS). The samples were then mounted on carbon-coated stubs and imaged on a field-emission scanning electron microscope (Zeiss Leo) at $1 \mathrm{kV}$ (at $1024 \times 628$ resolution).

\section{Pathology}

The canine brains were fixed whole in 10\% NBF (tissue-to-fixative ratio $>1: 10$ ) for 7 days and processed (paraffinized) for histology. The brains were sliced and stained with $\mathrm{H} \& \mathrm{E}$, and a veterinary pathologist performed the histopathological evaluation.

\section{Results}

\section{Induction of Ventricular Shunt Infection}

All 3 animals underwent successful ventricular shunt insertion surgery and recovered postoperatively. One experimental animal developed symptoms of elevated intracranial pressure (ICP) the evening of surgery and required administration of mannitol, after which there was complete resolution of symptoms. Between 4 and 7 days following initial implantation surgery, all animals demonstrated signs of wound infection, with purulent incisional drainage and partial dehiscence. Despite this, the animals remained without lethargy, fever, or clinical signs of neurological dysfunction. To minimize animal distress, each animal was taken back to the operating room for wound reexploration, washout with antibiotic irrigation $(1 \mathrm{~g}$ of Ancef in $1 \mathrm{~L}$ of normal saline), and wound revision. In all cases of reexploration, frank purulence was noted in the subgaleal space. All animals remained neurologically intact and survived until the completion of the experiment. 


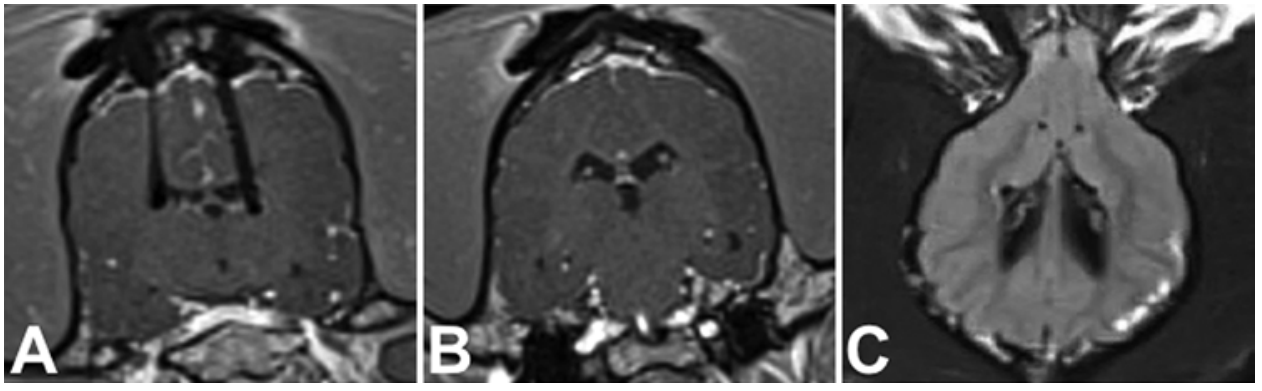

FIG. 1. Immediate postimplantation and postinoculation images obtained in 1 control animal (catheters without antibiotics). A and B: Preoperative coronal T1-weighted postcontrast MR images demonstrating bilateral ventricular catheter placement immediately after catheter implantation and bacterial inoculation. C: Axial T2-weighted FLAIR MR image obtained immediately after catheter insertion and bacterial inoculation demonstrating no associated cerebral edema.

Animals were afebrile, clinically normal, and displayed appropriate feeding behavior.

\section{MR Imaging}

Each animal underwent an immediate postimplantation MRI (Fig. 1) and an identical imaging study prior to being euthanized. In all 3 animals, the proximal catheters were confirmed to be traversing the ventricular system. Comparison of the effects of the bacterial inoculation was possible by comparing immediate postoperative images with interval scans prior to catheter harvest. In all animals, catheter-associated contrast enhancement and ventricular enhancement were apparent (Fig. 2). Additionally, the development of moderate to severe cerebral edema and inflammation was evidenced by FLAIR hyperintensity in the subcortical regions. No animal developed hydrocephalus or ischemic insults on DWI.

\section{Microbiology}

Shunt catheter tip culture results are summarized in Table 1. In the control animal, neither CSF nor blood cultures demonstrated organism growth. Bilateral shunt catheters demonstrated $S$. aureus growth following sonication and direct plating, with $6 \times 10^{4}$ CFUs growing from the left shunt and $9.5 \times 10^{5}$ CFUs from the right. Superficial and deep tract parenchymal biopsies demonstrated variable CFU growth of S. aureus. All colonies were susceptible to oxacillin and vancomycin.
In the first experimental animal, the CSF culture was negative, while the blood culture demonstrated growth of Streptococcus bovis and S. aureus. Following sonication, the left shunt catheter grew $2.4 \times 10^{6}$ CFUs of $S$. aureus, while the right shunt catheter had no growth of $S$. aureus. Parenchymal tissue from the left side grew S.aureus, but right-sided parenchymal biopsies demonstrated no growth. All bacterial species grown were susceptible to both oxacillin and vancomycin.

In the second experimental animal, blood and CSF cultures were negative. The left shunt catheter demonstrated no growth, and the right catheter demonstrated $10 \mathrm{CFUs}$ of $S$. aureus, and no growth after 1 and 2 serial dilutions. All bacterial species grown were susceptible to both oxacillin and vancomycin. Superficial parenchymal tissue demonstrated $S$. aureus growth, but deep biopsies demonstrated no growth.

\section{Electron Microscopy}

Shunt catheter tips from all animals as well as a nonimplanted, polymer-coated control catheter were analyzed using scanning electron microscopy (SEM; Fig. 3). Microscopy of the nonimplanted catheter demonstrated the presence of the polymer coating on its inner and outer surfaces, as well as discontinuities and breaks in a nonuniform pattern, but without occlusion of the catheter fenestrations (Fig. 3A-C).

Shunt tips from the implanted catheters were also eval-
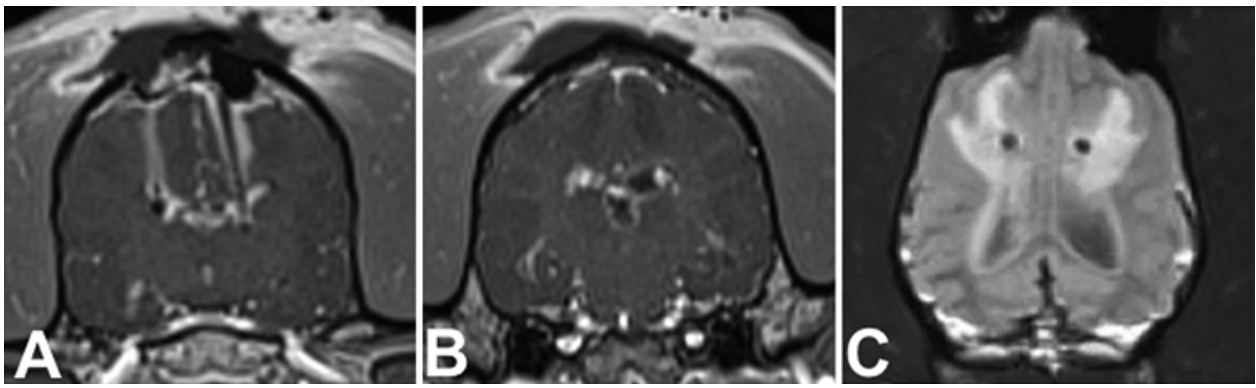

FIG. 2. Interval postoperative images of shunt infection and ventriculitis. A and B: Nine days following shunt catheter insertion and bacterial inoculation, repeat MR images demonstrate significant catheter-associated contrast enhancement (A) and ventricular lining enhancement (B), indicative of shunt infection and ventriculitis. C: Moderate to severe cerebral edema is also evident on the T2-weighted FLAIR MR image. 
TABLE 1. Quantitative and qualitative culture results

\begin{tabular}{|c|c|c|c|}
\hline Animal \& Side & Direct Plating & CSF & Blood \\
\hline \multicolumn{4}{|l|}{ Control } \\
\hline $\mathrm{Lt}$ & $\begin{array}{c}6 \times 10^{4} \text { CFUs } \\
\text { S. aureus }\end{array}$ & \multirow{2}{*}{ No growth } & \multirow{2}{*}{ No growth } \\
\hline Rt & $\begin{array}{c}9.5 \times 10^{5} \text { CFUs } \\
\text { S. aureus }\end{array}$ & & \\
\hline \multicolumn{4}{|l|}{ Experimental 1} \\
\hline $\mathrm{Lt}$ & $\begin{array}{c}2.4 \times 10^{6} \mathrm{CFUs} \\
\text { S. aureus }\end{array}$ & \multirow[t]{2}{*}{ No growth } & \multirow{2}{*}{$\begin{array}{l}\text { S. aureus, Strep- } \\
\text { tococcus bovis }\end{array}$} \\
\hline Rt & No growth & & \\
\hline \multicolumn{4}{|l|}{ Experimental 2} \\
\hline $\mathrm{Lt}$ & No growth & \multirow[b]{2}{*}{ No growth } & \multirow[b]{2}{*}{ No growth } \\
\hline Rt & $\begin{array}{c}10 \text { CFUs S. } \\
\text { aureus }\end{array}$ & & \\
\hline
\end{tabular}

uated using SEM. In catheters containing no antibiotics, as well as catheters with antibiotic impregnation that demonstrated $S$. aureus growth, significant buildup of bacteria and debris was found in the shunt fenestrations (Fig. 3D-F). Additionally, bacterial colonies could be identified on both the inner and outer surfaces of the catheter. For shunt tips of catheters with antibiotics that $\operatorname{did}$ not grow $S$. aureus, some debris was visible at high magnification, but the appearance was overall similar to the control catheter that had not been implanted in vivo (Fig. 3G-I).

\section{Pathology}

Histopathological evaluation of all 3 animal brains demonstrated evidence of acute inflammation consisting of suppurative and lymphocytic meningoencephalitis and foreign body response consisting of multinucleated giant cells engulfing foreign material. Evaluation of the control animal revealed predominantly suppurative and lymphocytic infiltration of the choroid plexus and ependymal/subependymal inflammation with perivascular cuffing (Fig. 4). The brains of experimental animals also demonstrated evidence of ventriculitis and encephalitis, but to a lesser extent, with less of a suppurative component when compared to the control specimen.

\section{Discussion}

In the modern era of neurosurgery, ventricular shunt infection remains a highly morbid and costly complication in both pediatric and adult populations. Recent attempts to reduce the incidence of shunt infection have mainly focused on modifiable risk factors, such as perioperative

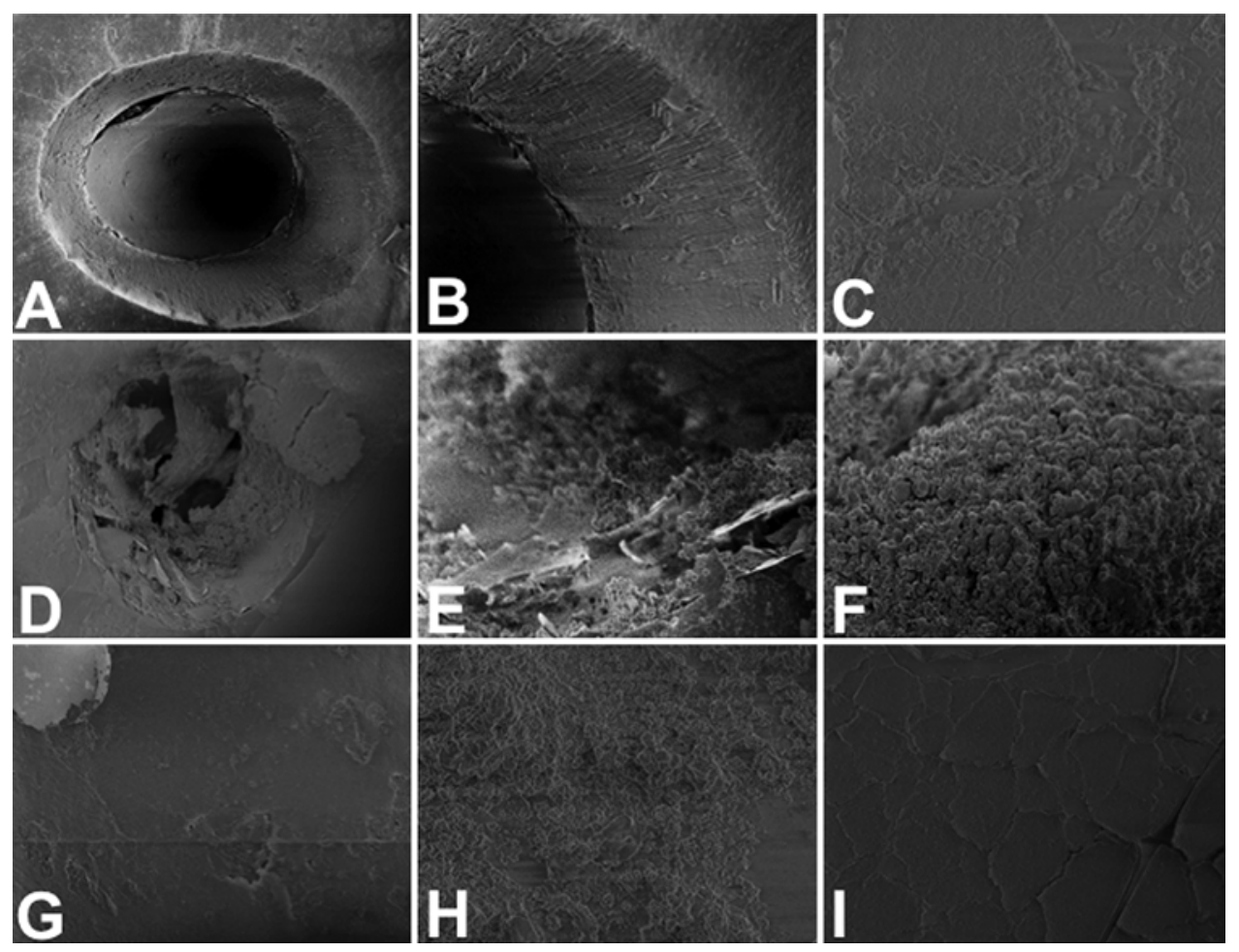

FIG. 3. Shunt catheter electron microscopy. A-C: Electron micrographs (EMs) of a nonimplanted shunt catheter coated with experimental polymer demonstrating association of the polymer with the catheter fenestrations ( $A$ and $B$ ) and catheter inner surface (C). D-F: EMs of harvested shunt catheters after implantation and bacterial inoculation demonstrated bacterial adherence to the catheter surface in clusters and colonies in both antibiotic-untreated ( $D$ and $E$ ) and antibiotic-treated $(F)$ catheters that grew significant bacteria after microbiological processing. Debris is seen clogging the catheter fenestration (D). G-I: EMs of harvested shunt catheters after implantation and bacterial inoculation demonstrated no bacterial adherence in antibiotic-treated catheters $(\mathrm{G}-\mathrm{I})$ that demonstrated no bacterial growth after microbiological processing. 


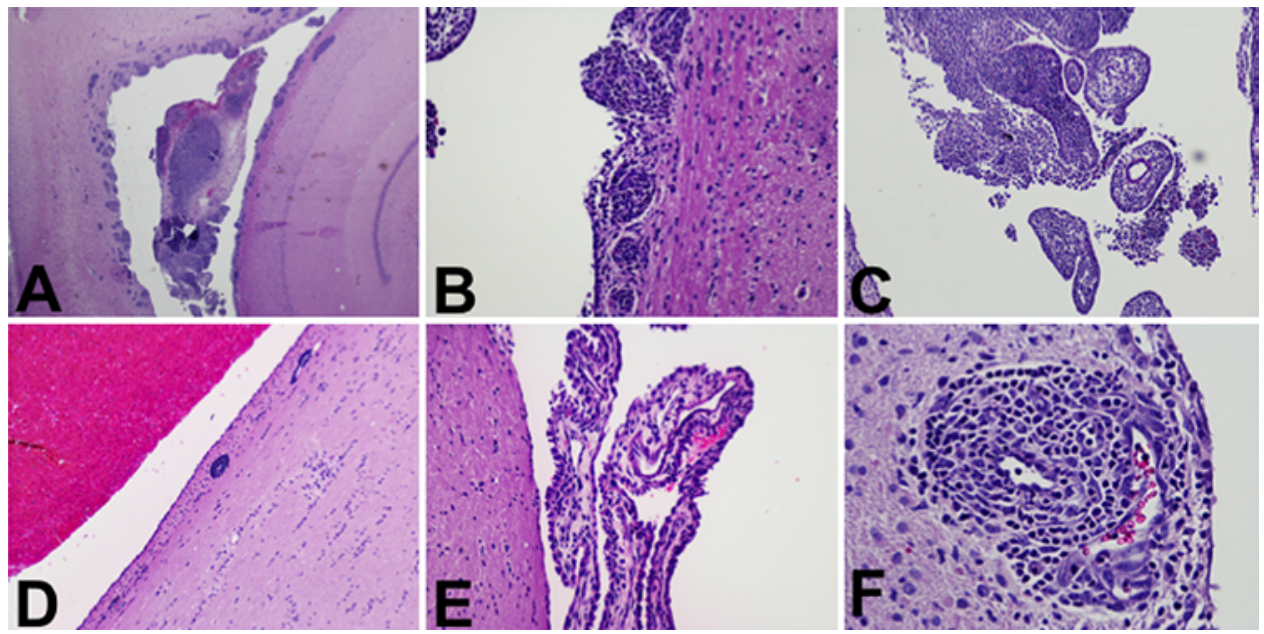

FIG. 4. Histopathological evaluation with H \& E. A: Light micrograph at $4 \times$ magnification demonstrating significant ventriculitis and choroid plexus inflammation in the control animal after antibiotic-untreated catheter implantation, bacterial inoculation, and interval harvest. Note significant periventricular ependymal and subependymal perivascular lymphocytic infiltrates and dense choroid plexus inflammatory infiltration. B and C: Light micrographs obtained in the control animal at 10x magnification, demonstrating perivascular lymphocytic infiltrates (B) and choroid plexus suppurative and lymphocytic infiltration (C). D-F: In an experimental animal with AIC insertion and bacterial inoculation, periventricular $(D)$ and choroid plexus (E) inflammation is still present, but to a lesser degree. Figure is available in color online only.

antibiotics, and intraoperative techniques, such as double gloving, no-touch handling of shunt hardware, and minimization of operating room traffic. ${ }^{26,27}$

In the last decade or so, the introduction and advent of AICs has been encouraging in the effort against shunt infection, with several reports and meta-analyses suggesting a reduced incidence and relative cost-effectiveness with their implementation. ${ }^{4,5,28,30,34,40}$ AICs have been designed to provide catheter resistance against gram-positive bacterial colonization resulting from the gradual and finite release of antibiotics targeted toward skin flora in the intraoperative and immediate postoperative settings. These features are practical, given that the majority of shunt infections are caused by gram-positive organisms and occur shortly after shunt surgery, likely due to colonization of the catheter at the time of insertion or revision. ${ }^{3,31,32,39}$ In some cases, traditional AICs are not effective, as evidenced by delayed infections that occur without immediately antecedent shunt surgery, as well as shunt infections caused by gram-negative bacteria. ${ }^{38,41,44,48}$ While the majority of evidence points to the utility of current AICs in reducing shunt infection rates, some studies cast uncertainty on their definitive efficacy and highlight the need for alternative antimicrobials or other catheter strategies..$^{24,26}$ Given the continued occurrence of shunt infection despite standardized multiinstitutional protocols and technological improvements, it is imperative that continued, vigilant investigation of this phenomenon occurs.

Preliminary studies of antimicrobial impregnation of catheters were performed in the 1970 s and 1980 s, when Bayston and colleagues methodically demonstrated the technique, durability, and effectiveness of silastic elastomers impregnated with antibiotics in vitro..$^{6,9,11,12}$ Further efforts across groups to evaluate the efficacy of AICs in vivo have also been described. ${ }^{8,20,35}$ The need for more robust exploration led to the generation of canine models of hydrocephalus and shunt infection. ${ }^{8,23}$ The benefits of using a large animal model for these purposes include the ability to implant and investigate actual shunt hardware utilized in human procedures, the interspecies similarity in ventricular anatomy, and the ability to monitor animals in a clinically meaningful way. However, these models have been limited by the lack of ability to rigorously quantify the presence of bacterial species on catheters and in parenchyma, the lack of variability of bacterial species used, especially more virulent strains, and the lack of ability to provide imaging correlates to ventricular infection and associated inflammation when virulent strains are present.

In this study, we evaluated a large animal model of shunting, enabling us to investigate a potential novel therapeutic catheter modification for shunt infection. We induced shunt infection by inoculation with a clinical strain of methicillin-sensitive $S$. aureus, a common etiological organism for shunt infection. We utilized a large inoculation dose in order to ensure that signs of infection could be induced in our small cohort of animals. Due to the high inoculation concentration, all animals displayed clinical signs of wound infection, requiring additional wound revision procedures. All animals similarly had imaging and histopathological evidence of ventricular infection and encephalitis.

An ideal animal model for hydrocephalus and CSF shunting would be one in which procedures similar to those performed in humans can be conducted, and one that allows for routine clinical evaluation, neuroimaging, and quantification of infection. Our model satisfies these needs and is advantageous in that empirical testing of various catheter modifications is possible. We feel that our study improves on previous in vivo studies of ventricular shunting by providing a model for shunt infection that can be easily recapitulated and tested.

While our goal was primarily to establish a large ani- 
mal model for shunt infection in a proof-of-principle study, we also utilized this model to concurrently investigate a drug-loaded polymer affixed to the ventricular catheter surface. There has been recent interest in the creation of durable synthetic coatings that can be treated with antibiotics to prevent hardware infection. ${ }^{21,45}$ As such, we modified shunt catheters with cross-linked polymers and antibiotic loading, but were unable to fully abolish ventriculitis or bacterial presence at the catheter surface when they were empirically tested. This result was not unexpected given the large bacterial burden delivered, and the preliminary nature of the polymer coating. Currently approved AICs are characterized by antibiotic impregnation into the shunt polymer itself due to their inherent solubility in the solvents used to swell shunt polymers. Investigation of shunt catheter coatings as an alternative to catheter impregnation has been performed, with a focus on adhesionfree coating properties. ${ }^{15}$ However, no antimicrobial and adhesion-free coating has been approved for widespread use. The investigational catheter coating used in this study can be applied on top of the native shunt polymer and is amenable to the delivery of a broad range of antibiotics, drug reapplication, reduced cell adhesion, and improved drug stability. In our study, bacterial quantification from catheter surfaces and histopathological evaluation demonstrated a trend toward decreased bacterial burden and tissue inflammation in the antibiotic-treated group, which highlights a promising avenue for further exploration and investigation.

Our study is not without limitations. Our limited sample size prohibits conclusions regarding the therapeutic efficacy of the cross-linked polymer utilized, although it was sufficient to yield a reproducible model of shunt infection. Additionally, we did not induce hydrocephalus in our animal cohort, which, together with stereotaxy, will aid in precise ventricular catheter placement in future studies utilizing this model and allow for evaluation of infection spread in a working shunt. ${ }^{23}$ Furthermore, there was heterogeneity in the interval between inoculation and harvest/sacrifice surgeries, as the control animal underwent harvest 2 days earlier than the experimental animals due to logistical facility limitations. Nonetheless, given the increased severity of inflammatory and infectious findings in our control animal, it is highly unlikely that a longer observation period would have yielded a different result. Further, use of a high bacterial concentration resulted in severe ventricular infection in our model, which we acknowledge is not traditionally found in shunt infections caused by less virulent strains. These bacterial concentrations are likely higher than those found in shunt infections in humans. Despite high inoculation doses of bacteria, CSF cultures remained negative in all animals. It is not clear why this phenomenon occurred, as histopathology revealed meningoencephalitis, but it is possible that future studies incorporating induced hydrocephalus and functional shunts would yield positive CSF cultures. It is possible that the purulent material within the ventricular system resulted in scarring and inflammation resulting in a lack of communication between the cisterna magna, where CSF cultures were obtained, and the rest of the ventricular system. In future studies, stereotactically placed ventricular catheters into induced hydrocephalic ventricles would allow us to directly sample fully functioning shunts. Furthermore, it is possible that superficial irrigation of cefazolin-containing solution during wound washout affected our culture results. It is unlikely that this low dose of antibiotic affected intracranial culture results when administered subcutaneously, but this subtherapeutic antibiotic administration could have affected other normal flora, leading to a superinfection with $S$. aureus. Adjusting the concentration of inoculated bacteria in future experiments will help to reduce the "ceiling" of clinical, neuroimaging, and histopathological features of shunt infection in all animals in order to more effectively determine relevant therapeutic differences when testing novel catheter modifications.

\section{Conclusions}

We successfully modified and evaluated a large animal model of ventricular shunting and reliably induced clinical, neuroimaging, and histopathological features of shunt infection, which also allowed for quantification of bacterial burden. Using this model, we explored a promising shunt catheter polymer coating with antimicrobial-loading and reloading properties. With this model, further investigation of potentially beneficial shunt catheter modifications is possible.

\section{Acknowledgments}

We thank Melanie Albano and Krystie Koenig for providing excellent animal care in the perioperative setting. We would also like to thank Shawna Davis, Lisa Dam, Susan Henciak, and JoAnne Miller for assistance with catheter sonication and microbiological cultures.

Funding for this work was provided by a Case-Coulter Translational Research Partnership award.

\section{References}

1. Ammirati M, Raimondi AJ: Cerebrospinal fluid shunt infections in children. A study on the relationship between the etiology of hydrocephalus, age at the time of shunt placement, and infection rate. Childs Nerv Syst 3:106-109, 1987

2. Animal Welfare Act as Amended, 7 USC \$2131-2159, 2008

3. Arnell K, Cesarini K, Lagerqvist-Widh A, Wester T, Sjölin $\mathrm{J}$ : Cerebrospinal fluid shunt infections in children over a 13year period: anaerobic cultures and comparison of clinical signs of infection with Propionibacterium acnes and with other bacteria. J Neurosurg Pediatr 1:366-372, 2008

4. Aryan HE, Meltzer HS, Park MS, Bennett RL, Jandial R, Levy ML: Initial experience with antibiotic-impregnated silicone catheters for shunting of cerebrospinal fluid in children. Childs Nerv Syst 21:56-61, 2005

5. Attenello FJ, Garces-Ambrossi GL, Zaidi HA, Sciubba DM, Jallo GI: Hospital costs associated with shunt infections in patients receiving antibiotic-impregnated shunt catheters versus standard shunt catheters. Neurosurgery 66:284-289, 2010

6. Bayston R: Preliminary studies on the impregnation of silastic elastomers with antimicrobial substances. Dev Med Child Neurol Suppl (37):50-54, 1976

7. Bayston R, Ashraf W, Bhundia C: Mode of action of an antimicrobial biomaterial for use in hydrocephalus shunts. $\mathbf{J}$ Antimicrob Chemother 53:778-782, 2004

8. Bayston R, Brant C, Dombrowski SM, Hall G, Tuohy M, Pro- 
cop G, et al: An experimental in-vivo canine model for adult shunt infection. Cerebrospinal Fluid Res 5:17, 2008

9. Bayston R, Grove N, Siegel J, Lawellin D, Barsham S: Prevention of hydrocephalus shunt catheter colonisation in vitro by impregnation with antimicrobials. J Neurol Neurosurg Psychiatry 52:605-609, 1989

10. Bayston R, Lari J: A study of the sources of infection in colonised shunts. Dev Med Child Neurol 16 (6 Suppl 32):16-22, 1974

11. Bayston R, Milner RD: Antimicrobial activity of silicone rubber used in hydrocephalus shunts, after impregnation with antimicrobial substances. J Clin Pathol 34:1057-1062, 1981

12. Bayston R, Zdroyewski V, Barsham S: Use of an in vitro model for studying the eradication of catheter colonisation by Staphylococcus epidermidis. J Infect 16:141-146, 1988

13. Beckman JM, Amankwah EK, Tetreault LL, Tuite GF: Reduction in CSF shunt infection over a 10 -year period associated with the application of concentrated topical antibiotic powder directly to surgical wounds prior to closure. J Neurosurg Pediatr 16:648-661, 2015

14. Blount JP, Campbell JA, Haines SJ: Complications in ventricular cerebrospinal fluid shunting. Neurosurg Clin N Am 4:633-656, 1993

15. Chen HH, Riva-Cambrin J, Brockmeyer DL, Walker ML, Kestle JR: Shunt failure due to intracranial migration of BioGlide ventricular catheters. J Neurosurg Pediatr 7:408-412, 2011

16. Cochrane DD, Kestle JR: The influence of surgical operative experience on the duration of first ventriculoperitoneal shunt function and infection. Pediatr Neurosurg 38:295-301, 2003

17. Committee for the Update of the Guide for the Care and Use of Laboratory Animals: Guide for the Care and Use of Laboratory Animals, ed 8. Washington, DC: National Academies Press, 2011

18. Faillace WJ: A no-touch technique protocol to diminish cerebrospinal fluid shunt infection. Surg Neurol 43:344-350, 1995

19. Halpern JM, Gormley CA, Keech M, von Recum HA: Thermomechanical properties, antibiotic release, and bioactivity of a sterilized cyclodextrin drug delivery system. J Mater Chem B Mater Biol Med 2:2764-2772, 2014

20. Hampl J, Schierholz J, Jansen B, Aschoff A: In vitro and in vivo efficacy of a rifampin-loaded silicone catheter for the prevention of CSF shunt infections. Acta Neurochir (Wien) 133:147-152, 1995

21. Harth KC, Rosen MJ, Thatiparti TR, Jacobs MR, Halaweish I, Bajaksouzian S, et al: Antibiotic-releasing mesh coating to reduce prosthetic sepsis: an in vivo study. J Surg Res 163:337-343, 2010

22. Hayhurst C, Cooke R, Williams D, Kandasamy J, O'Brien DF, Mallucci CL: The impact of antibiotic-impregnated catheters on shunt infection in children and neonates. Childs Nerv Syst 24:557-562, 2008

23. Johnson MJ, Ayzman I, Wood AS, Tkach JA, Klauschie J, Skarupa DJ, et al: Development and characterization of an adult model of obstructive hydrocephalus. J Neurosci Methods 91:55-65, 1999

24. Kan P, Kestle J: Lack of efficacy of antibiotic-impregnated shunt systems in preventing shunt infections in children. Childs Nerv Syst 23:773-777, 2007

25. Kandasamy J, Dwan K, Hartley JC, Jenkinson MD, Hayhurst $\mathrm{C}$, Gatscher S, et al: Antibiotic-impregnated ventriculoperitoneal shunts-a multi-centre British paediatric neurosurgery group (BPNG) study using historical controls. Childs Nerv Syst 27:575-581, 2011

26. Kestle JR, Holubkov R, Douglas Cochrane D, Kulkarni AV, Limbrick DD Jr, Luerssen TG, et al: A new Hydrocephalus Clinical Research Network protocol to reduce cerebrospinal fluid shunt infection. J Neurosurg Pediatr 17:391-396, 2016
27. Kestle JR, Riva-Cambrin J, Wellons JC III, Kulkarni AV, Whitehead WE, Walker ML, et al: A standardized protocol to reduce cerebrospinal fluid shunt infection: the Hydrocephalus Clinical Research Network Quality Improvement Initiative. J Neurosurg Pediatr 8:22-29, 2011

28. Klimo P Jr, Thompson CJ, Baird LC, Flannery AM: Pediatric hydrocephalus: systematic literature review and evidencebased guidelines. Part 7: Antibiotic-impregnated shunt systems versus conventional shunts in children: a systematic review and meta-analysis. J Neurosurg Pediatr 14 (Suppl 1):53-59, 2014

29. Kockro RA, Hampl JA, Jansen B, Peters G, Scheihing M, Giacomelli R, et al: Use of scanning electron microscopy to investigate the prophylactic efficacy of rifampin-impregnated CSF shunt catheters. J Med Microbiol 49:441-450, 2000

30. Konstantelias AA, Vardakas KZ, Polyzos KA, Tansarli GS, Falagas ME: Antimicrobial-impregnated and -coated shunt catheters for prevention of infections in patients with hydrocephalus: a systematic review and meta-analysis. J Neurosurg 122:1096-1112, 2015

31. Kontny U, Höfling B, Gutjahr P, Voth D, Schwarz M, Schmitt HJ: CSF shunt infections in children. Infection 21:89-92, 1993

32. Kulkarni AV, Drake JM, Lamberti-Pasculli M: Cerebrospinal fluid shunt infection: a prospective study of risk factors. J Neurosurg 94:195-201, 2001

33. Office of Laboratory Animal Welfare: Public Health Service Policy on Humane Care and Use of Laboratory Animals. Bethesda: National Institutes of Health, 2015 (https://grants.nih.gov/grants/olaw/references/ phspolicylabanimals.pdf) [Accessed March 1, 2018]

34. Parker SL, Attenello FJ, Sciubba DM, Garces-Ambrossi GL, Ahn E, Weingart J, et al: Comparison of shunt infection incidence in high-risk subgroups receiving antibioticimpregnated versus standard shunts. Childs Nerv Syst 25:77-85, 2009

35. Pattavilakom A, Kotasnas D, Korman TM, Xenos C, Danks A: Duration of in vivo antimicrobial activity of antibioticimpregnated cerebrospinal fluid catheters. Neurosurgery 58:930-935, 2006

36. Ragel BT, Browd SR, Schmidt RH: Surgical shunt infection: significant reduction when using intraventricular and systemic antibiotic agents. J Neurosurg 105:242-247, 2006

37. Ratilal B, Costa J, Sampaio C: Antibiotic prophylaxis for surgical introduction of intracranial ventricular shunts: a systematic review. J Neurosurg Pediatr 1:48-56, 2008

38. Schiff SJ, Oakes WJ: Delayed cerebrospinal-fluid shunt infection in children. Pediatr Neurosci 15:131-135, 1989

39. Sciubba DM, McGirt MJ, Woodworth GF, Carson B, Jallo GI: Prolonged exposure to antibiotic-impregnated shunt catheters does not increase incidence of late shunt infections. Childs Nerv Syst 23:867-871, 2007

40. Sciubba DM, Stuart RM, McGirt MJ, Woodworth GF, Samdani A, Carson B, et al: Effect of antibiotic-impregnated shunt catheters in decreasing the incidence of shunt infection in the treatment of hydrocephalus. J Neurosurg 103 (2 Suppl):131-136, 2005

41. Sells CJ, Shurtleff DB, Loeser JD: Gram-negative cerebrospinal fluid shunt-associated infections. Pediatrics 59:614-618, 1977

42. Simon TD, Butler J, Whitlock KB, Browd SR, Holubkov R, Kestle JR, et al: Risk factors for first cerebrospinal fluid shunt infection: findings from a multi-center prospective cohort study. J Pediatr 164:1462-1468, 2014

43. Simon TD, Hall M, Riva-Cambrin J, Albert JE, Jeffries HE, Lafleur B, et al: Infection rates following initial cerebrospinal fluid shunt placement across pediatric hospitals in the United States. Clinical article. J Neurosurg Pediatr 4:156-165, 2009 
44. Stamos JK, Kaufman BA, Yogev R: Ventriculoperitoneal shunt infections with gram-negative bacteria. Neurosurgery 33:858-862, 1993

45. Thatiparti TR, Shoffstall AJ, von Recum HA: Cyclodextrinbased device coatings for affinity-based release of antibiotics. Biomaterials 31:2335-2347, 2010

46. Tulipan N, Cleves MA: Effect of an intraoperative doublegloving strategy on the incidence of cerebrospinal fluid shunt infection. J Neurosurg 104 (1 Suppl):5-8, 2006

47. Vinchon M, Dhellemmes P: Cerebrospinal fluid shunt infection: risk factors and long-term follow-up. Childs Nerv Syst 22:692-697, 2006

48. Vinchon M, Lemaitre MP, Vallée L, Dhellemmes P: Late shunt infection: incidence, pathogenesis, and therapeutic implications. Neuropediatrics 33:169-173, 2002

\section{Disclosures}

Dr. Blitz: prior indirect research support from Aesculap. Dr. Zuckerman: employee of Affinity Therapeutics, LLC. Dr. von
Recum: ownership in Affinity Therapeutics, LLC. Dr. Luciano: consultant for Codman.

\section{Author Contributions}

Conception and design: Luciano, Iyer, Gorelick, Carroll, Blitz, Tyler, Capadona, von Recum. Acquisition of data: Luciano, Iyer, Gorelick, Carroll, Blitz, Beck, Garrett, Tyler, Zuckerman, von Recum. Analysis and interpretation of data: Luciano, Iyer, Gorelick, Carroll, Blitz, Beck, Tyler, von Recum. Drafting the article: Iyer. Critically revising the article: Luciano, Iyer, Carroll, Blitz, Beck, Garrett, Tyler, Capadona, von Recum. Reviewed submitted version of manuscript: all authors. Approved the final version of the manuscript on behalf of all authors: Iyer. Administrative/ technical/material support: Luciano, Carroll, Garrett, Tyler, Zuckerman, Capadona, von Recum. Study supervision: Luciano, von Recum.

\section{Correspondence}

Mark G. Luciano: Johns Hopkins University School of Medicine, Baltimore, MD.markluciano@jhu.edu. 